Jurnal IImu Teknik Elektro Komputer dan Informatika (JITEKI)

Vol. 2, No. 2, Desember 2016

\title{
SISTEM PRESENSI MAHASISWA BERBASIS RFID MENGGUNAKAN RASPBERRY PI 1
}

\author{
Nurwahyuddi \\ Program Studi Teknik Elektro Universitas Ahmad Dahlan Yogyakarta \\ Jln. Prof. Dr. Supomo Yogyakarta. TIp. 0274-379418, Fax. 0274-381523 \\ email: nurwahyoeddy@gmail.com
}

\begin{abstract}
Student attendance system currently still a lot do with the signing of presence sheets manually. However, this of course is assessed as slow and less efficient both in term of time or effort. In addition, the manual presence can also cause interference and break up the concentration of student while carrying out lecture. These problems can interfere with students focus in listening to a lecture by profesor material exposure because the presence books should be rolled out to every student. Therefore, student attendance system RFID based using Rasperry Pi 1 are expected to deal with problems that arise due to presence. System designed in this research made by using RFID modules MIFARE RC522 type and Rasperry Pi 1 type B+ as a major component of the system. In general, there are three activities that will be carried out by the system, i.e receive input form result of identification ID card tags, processing input results identification ID by Rasperry $\mathrm{Pi}$ and decide the response system and produce presence recapitulation data on the server Rasperry Pi. The results of the presence will be displayed on the LCD $16 \times 2$ featuring the name of students as well as the courses that are being followed. As a result, server will send the presence data and will be displayed on the client computer through a website that display presence date, the name of student, the number of student (NIM) and the name of the course that is being followed. Testing on student attendance system RFID based using Rasperry Pi producing largest distance card identification on tags as far $4.5 \mathrm{~cm}$ with an average reading time for $38 \mathrm{~ms}$. In addition, the study also proved that a metal barrier can clock the process of identification card tags by RFID reader, so card tag cannot be read. However, But on another type of barrier, such as glass, rubber, ceramic, acrylic, and wood used for testing does not affect the process of identification card tag successfully performed and does not affect the reading of cards, both in terms of distance or time readings.
\end{abstract}

Keywords: attendance RFID system; RFID module-MFRC522; raspberry pi.

\begin{abstract}
Abstrak
Sistem presensi mahasiswa saat ini masih banyak dilakukan dengan penandatanganan lembar kehadiran secara manual. Hal ini tentu saja dinilai lambat dan kurang efisien, baik dari segi waktu maupun proses pengolahan datanya. Presensi manual juga dapat menimbulkan gangguan dan memecah konsentrasi mahasiswa saat melaksanakan perkuliahan. Masalah tersebut dapat mengganggu fokus mahasiswa dalam mendengarkan pemaparan materi perkuliahan oleh dosen karena buku presensi harus digulirkan kepada setiap mahasiswa. Sistem presensi mahasiswa berbasis RFID menggunakan Raspberry Pi diharapkan mampu menangani masalah-masalah yang timbul akibat presensi yang dilakukan secara manual. Sistem yang dirancang pada penelitian ini dibuat dengan menggunakan modul RFID jenis MIFARE RC522 dan Raspberry Pi 2 tipe B+ sebagai komponen utama sistem. Secara umum, terdapat 3 aktivitas yang akan dikerjakan oleh sistem, yaitu menerima masukan berupa hasil identifikasi ID pada kartu tag, mengolah masukan hasil identifikasi ID oleh Raspberry Pi sekaligus menentukan respon sistem, dan menghasilkan rekapan data presensi pada server Raspberry Pi. Hasil presensi yang dilakukan akan ditampilkan pada LCD 16x2 yang menampilkan nama mahasiswa serta mata kuliah yang sedang diikuti. Sebagai hasil akhir, server akan mengirim data presensi dan akan ditampilkan pada komputer client melalui website yang menampilkan waktu presensi, tanggal presensi, nama mahasiswa, NIM, dan nama mata kuliah yang sedang diikuti. Pengujian pada sistem presensi mahasiswa berbasis RFID menggunakan Raspberry Pi menghasilkan jarak maksimal identifikasi kartu tag sejauh $4,5 \mathrm{~cm}$ dengan rata-rata waktu pembacaan selama $38 \mathrm{~ms}$. Selain itu, penelitian ini juga membuktikan bahwa penghalang jenis logam dapat menghalangi
\end{abstract}


proses identifikasi kartu tag oleh reader RFID, sehingga kartu tag tidak dapat terbaca. Namun pada jenis penghalang lain, seperti kaca, karet, kramik, acrilic, dan kayu yang digunakan untuk pengujian tidak mempengaruhi proses identifikasi kartu tag, baik dari segi jarak dan waktu pembacaan.

Kata Kunci: sistem presensi RFID; modul RFID-MFRC522; raspberry pi.

\section{Pendahuluan}

Presensi merupakan rutinitas yang diwajibkan bagi penuntut ilmu pengetahuan, baik di bangku Sekolah Dasar (SD), Sekolah Menengah Pertama (SMP), Sekolah Menengah Atas/Kejuruan (SMA/K) maupun pada jenjang perguruan tinggi. Presensi secara umum digunakan untuk membuktikan kehadiran seseorang, di sekolah, universitas, tempat kerja (instansi atau perusahaan), seminar, dan pelatihan. Oleh karena itu, fungsi presensi menjadi sangat penting, baik bagi kalangan pelajar, mahasiswa, maupun karyawan.

Sistem presensi saat ini banyak dilakukan dengan penandatanganan lembar kehadiran secara manual. Hal ini tentu saja dinilai lambat dan kurang efisien, baik dari segi waktu maupun tenaga. Pasalnya, hal tersebut dapat menimbulkan gangguan dan memecah konsentrasi, baik dalam melaksanakan perkuliahan maupun kegiatan lainnya. Dapat diambil contoh presensi perkuliahan misalnya, hal ini dapat mengganggu fokus mahasiswa dalam mendengarkan pemaparan materi perkuliahan oleh dosen karena buku presensi harus digulirkan kepada setiap mahasiswa. Sedangkan untuk presensi kegiatan, hal ini dapat menimbulkan antrian panjang ketika hendak menandatangani formulir kehadiran (Cahyadi, 2009).

Untuk mengatasi beberapa masalah di atas, perlu adanya solusi yang jitu guna menghindari dampak negatif yang ditimbulkan saat melakukan pendataan kehadiran. Oleh karena itu, dilakukan penelitian terhadap kemampuan RFID (Radio Frequency Identification) sebagai media access control yang dapat mengidentifikasi data mahasiswa melalui kartu tag RFID yang di dalamnya telah terkodekan nomor serial unik. Sebagai sistem kontrol, digunakan Raspberry Pi yang diimplementasikan sebagai mikrokontroler yang bertugas memprogram RFID agar dapat mengidentifikasi kode pada kartu tag. Sedangkan RFID bertugas sebagai media akses kontrol. Harapannya, penelitian ini dapat menghasilkan sistem yang praktis dan efisien membuat mahasiswa dapat langsung melakukan presensi dan membuktikan kehadirannya, sehingga meningkatkan keakurasian dalam mendata kehadiran (Cahyadi, 2009; Wibisono, 2015).

\section{Metode Penelitian}

\subsection{Bahan Penelitian}

1. Modul RFID MIFARE RC522 (seperti pada Gambar 1a) digunakan sebagai interogator untuk mengidentifikasi nomor serial kartu tag saat melakukan presensi.

2. Raspberry Pi yang digunakan yaitu Raspberry Pi 1 model B+ (seperti pada Gambar 1b). Raspberry Pi 1 model B+ merupakan tipe Raspberry Pi yang memiliki kelengkapan fitur yang cukup lengkap dibandingkan tipe keluaran sebelumnya, dan memiliki harga yang relatif murah.

3. Tag RFID yang digunakan berupa kartu (Tag Card) dengan frekuensi kerja $13,56 \mathrm{MHz}$.

4. LCD digunakan untuk menampilkan hasil identifikasi oleh reader RFID terhadap tag saat melakukan pembacaan ID tag. Display LCD yang digunakan adalah jenis LCD dot martix 16x02 warna putih (dapat dilihat pada Gambar 1c).

5. Micro SD yang digunakan yaitu merek Sundisk 8 GB class 10 sebagai memori yang digunakan pada Raspberry Pi.

6. Jumper Male to Female dan Female to Female.

7. Saklar digunakan sebagai saklar untuk menghidupkan dan mematikan modus pembacaan reader RFID.

8. Red LED sebagai penanda atau indikator sistem berupa cahaya.

9. Buzzer aktif $3 \mathrm{~V}$ yang berfungsi sebagai penanda atau indikator berupa suara.

10. Black Box berbahan plastik digunakan sebagai tempat penyatuan komponen sistem (Packing Box) dengan panjang $18 \mathrm{~cm}$, lebar, $11 \mathrm{~cm}$, tinggi $6 \mathrm{~cm}$, dan ketebalan bahan 3 $\mathrm{mm}$. 
11. Kabel UTP (Unshielded Twisted Pair) dengan socket RJ45, digunakan sebagai jalur komunikasi yang menghubungkan antara perangkat sistem yang dibangun dengan komputer web server. Kabel UTP yang digunakan menggunakan sistem pengkabelan Cross yang dapat dimanfaatkan sebagai koneksi Point to Point antar 2 perangkat yang dihubungkan melalui Ethernet.

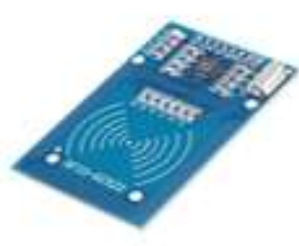

a

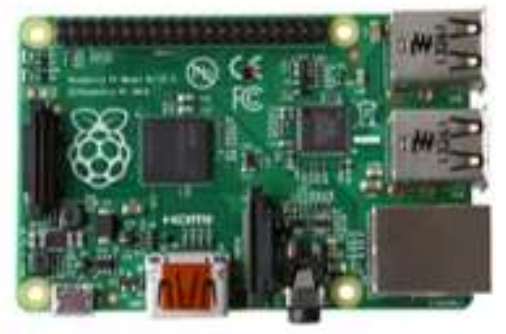

b

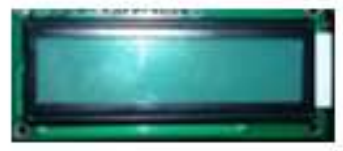

C

Gambar 1. (a) modul RFID MIFARE RC522; (b) raspberry pi 1 model B+; (c) LCD 16x2 character

\subsection{Alat Penelitian}

\subsubsection{Perangkat Keras}

1. Komputer/PC yang digunakan yaitu merek ASUS Notebook X200CA dengan Processor Intel Celeron Dual Core 2,16 GHz, SDRAM 2 GB, dan Hard Disk 500 GB.

2. Kabel USB digunakan untuk memberikan suplai tegangan untuk menghidupkan Raspberry Pi. Pada penelitian ini, sumber suplai tegangan untuk Raspberry Pi berasal dari tegangan laptop sebesar $5 \mathrm{~V}$ dan tidak menggunakan suplai langsung dari power supply adaptor USB yang ditancapkan pada Stop Contact.

3. Mistar, digunakan untuk mengukur jarak antara kartu tag dengan reader RFID saat melakukan pengujian jarak.

4. Camera Smartphone, digunakan untuk mendokumentasikan penelitian.

\subsubsection{Perangkat Lunak}

1. Win32 Disk Imager digunakan untuk menginstall OS (Operating System) Raspbian Jessie (OS khusus yang direkomendasikan untuk Raspberry Pi) ke dalam SD card agar dapat dijalankan pada board Raspberry Pi.

2. Sistem operasi yang digunakan dalam penelitian ini yaitu sistem operasi Raspbian Jessie versi 4.4. Raspbian Jessie merupakan sistem operasi khusus berbasis Debian yang dapat bekerja secara optimal pada mini komputer Raspberry $\mathrm{Pi}$

3. Python 2.7 dalam penelitian ini dimanfaatkan sebagai program creator and editor dalam pembuatan program sistem presensi mahasiswa berbasis RFID menggunakan Raspberry Pi.

4. LAMPP (Linux Apache MySQL Perl/PHP/Python) digunakan untuk membangun koneksi lokal antara server (Raspberry Pi) dan client (komputer host). Penelitian ini menggunakan software LAMPP (versi 3.2.1) sebagai local server Raspberry Pi.

5. Putty digunakan untuk melakukan remote access terhadap Raspberry Pi. Putty bekerja pada protokol SSH dan menjalankan sesi remote menggunakan jaringan lokal (LAN).

6. Remote dekstop connection digunakan untuk melakukan remote terhadap dekstop Raspberry $\mathrm{Pi}$ agar mempermudah dalam melakukan konfigurasi pada fitur-fitur dasar yang harus dijalankan pada Raspberry $\mathrm{Pi}$.

7. Browser digunakan untuk membuka halaman web localhost. Browser yang digunakan dalam penelitian ini yaitu Mozila Firefox versi 47.0.1.

\subsubsection{Prinsip Kerja Sistem}

Secara umum terdapat 3 aktivitas yang akan dikerjakan oleh sistem, yaitu menerima masukan berupa hasil identifikasi ID pada kartu tag, mengolah masukan hasil identifikasi ID oleh 
Raspberry Pi sekaligus menentukan respon sistem, dan menghasilkan rekapan data presensi yang ditampilkan pada komputer client.

Sistem presensi berbasis RFID menggunakan Raspberry Pi dimulai dengan inisialisasi database yang telah dibuat dan disimpan pada server lokal Raspberry Pi. Ketika sebuah tag dengan nomor ID tertentu masuk dalam jarak pembacaan reader, database yang telah terinisialisasi sebelumnya akan dikomparasikan dan dicocokkan dengan ID tag yang terbaca. Database akan mencari data mahasiswa yang cocok dengan kriteria ID tag yang terbaca oleh reader. Jika ID tag tersebut tidak dapat dikenali, maka pada LCD akan memberitahukan bahwa ID tag tersebut tidak dikenali. Namun jika ID tag dapat dikenali oleh sistem, maka sistem akan mencari nama mata kuliah yang sedang diikuti oleh pemilik ID tag tersebut. Dalam hal ini, terdapat 2 kemungkinan yang akan terjadi, yaitu mata kuliah ditemukan dan tidak ditemukan. Jika mata kuliah ditemukan atau sesuai dengan jam mata kuliah yang sedang berlangsung, maka LCD akan menampilkan nama mahasiswa dan nama mata kuliah yang diambil oleh mahasiswa tersebut. Tahap selanjutnya, sistem akan menyimpan data (merekap) hasil dari proses identifikasi ID tag yang dikenali dalam database berupa nama mahasiswa, NIM, nama mata kuliah, dan waktu presensi. Namun jika mata kuliah tidak ditemukan atau tidak sesuai dengan waktu mata kuliah yang terdata dalam server database, maka sistem akan memberitahukan melalui LCD bahwa nama mahasiswa yang memiliki ID tag tersebut tidak sedang mengikuti mata kuliah apapun. Output dari sistem presensi mahasiswa berbasis RFID menggunakan Rapsberry Pi ini adalah berupa hasil rekapan presensi yang disimpan dalam server lokal Raspberry Pi. Alur kerja sistem dapat dilihat pada Gambar 2.

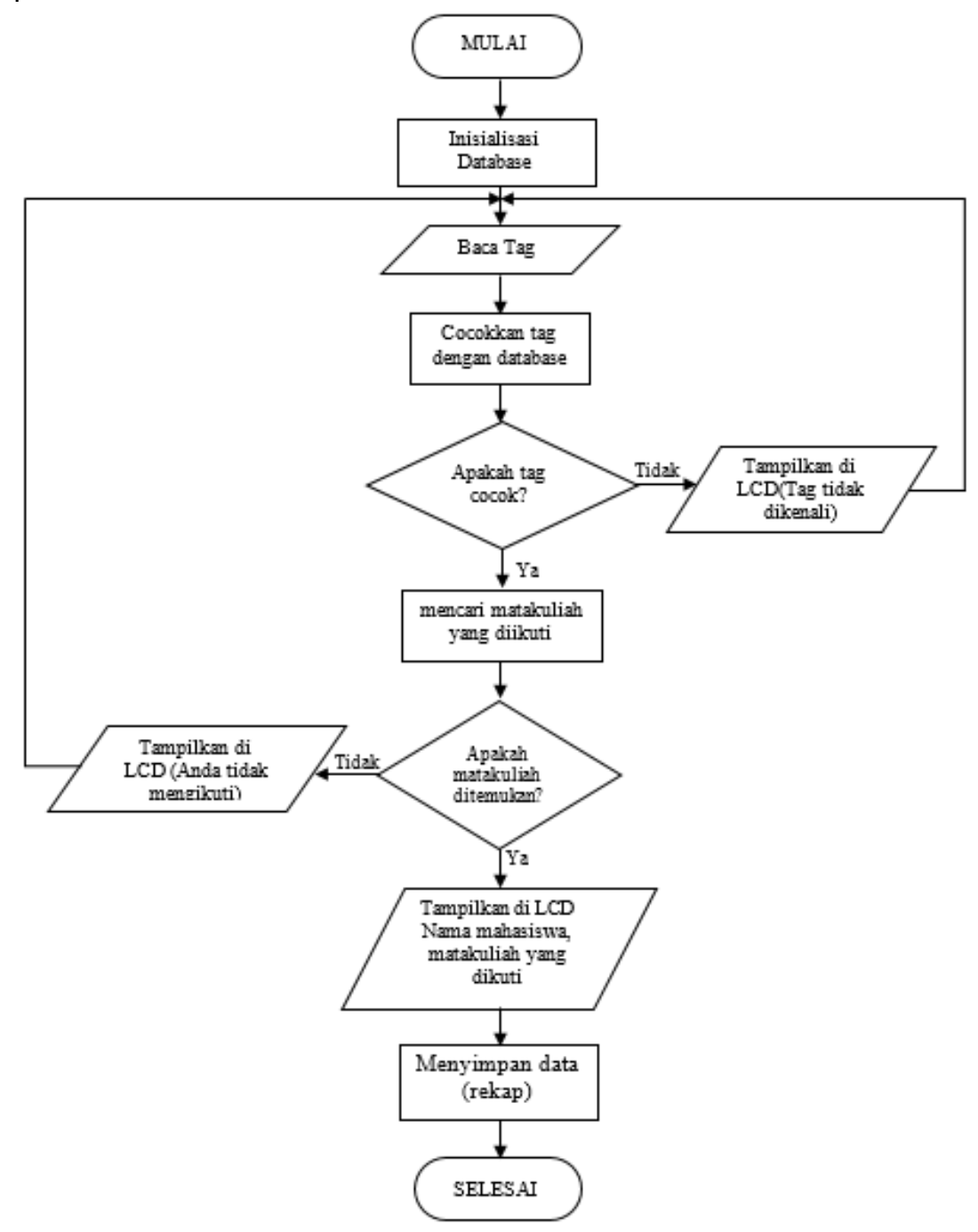

Gambar 2. Diagram alir kerja sistem 


\section{Hasil dan Pembahasan}

\subsection{Pengujian Koneksi}

Pengujian koneksi yaitu pengujian yang. Untuk memastikan koneksi jaringan antara client dan server dapat dilakukan dengan menuliskan "ping 192.168.137.5" pada command prompt client. Jika koneksi jaringan antara client dan server gagal, maka akan terlihat seperti Gambar 3.

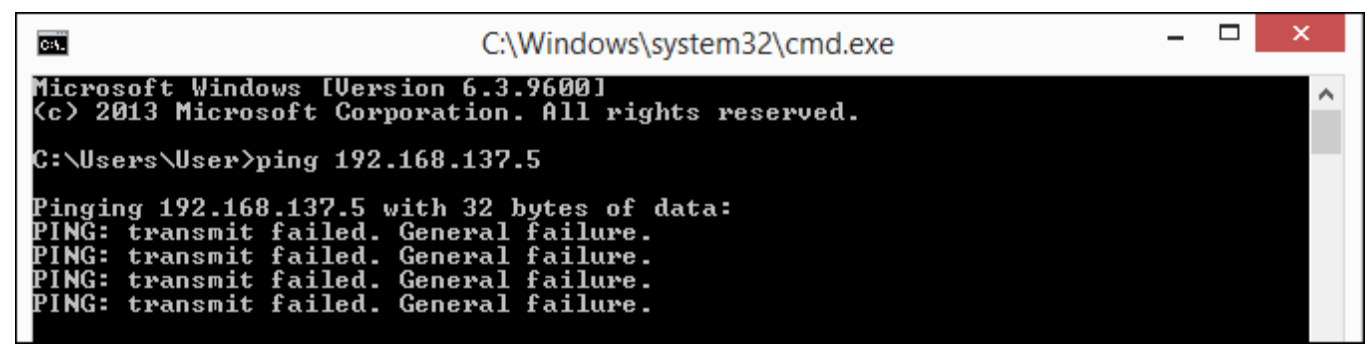

Gambar 3. Koneksi gagal antara client server

Hasil koneksi gagal disebabkan karena konfigurasi IP Address belum sesuai antara komputer client dan server Raspberry Pi. Kemudian lakukan konfigurasi IP Address pada TCP/lpv4 dengan IP 192.168.137.2, subnet mask 255.255.255.0, dan default gateway 192.168.137.1. Selanjutnya simpan konfigurasi yang telah dilakukan, kemudian panggil kembali IP Address server menggunakan perintah ping 192.168.137.5 pada command prompt seperti yang telah dilakukan sebelumnya. Jika ping IP Address server berhasil, maka akan muncul tampilan seperti Gambar 4

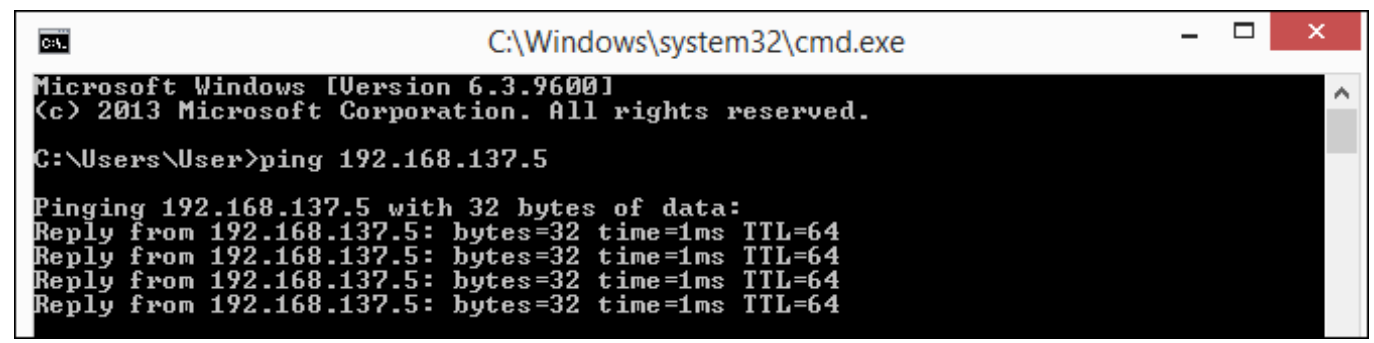

Gambar 4. Pembacaan koneksi telah berhasil

\subsection{Pengujian Jarak}

Pengujian jarak dilakukan untuk mengetahui berapa jauh jarak maksimal pembacaan ID tag oleh reader RFID melalui gelombang radio yang dipancarkan. Pengujian ini mengambil 16 sampel jarak yang diukur pada setiap $0,5 \mathrm{~cm}$. Masing-masing pada setiap jarak dilakukan pengujian sebanyak 10 kali pengujian. Cara pengujian ditunjukkan pada Gambar 5 dan Gambar 6.

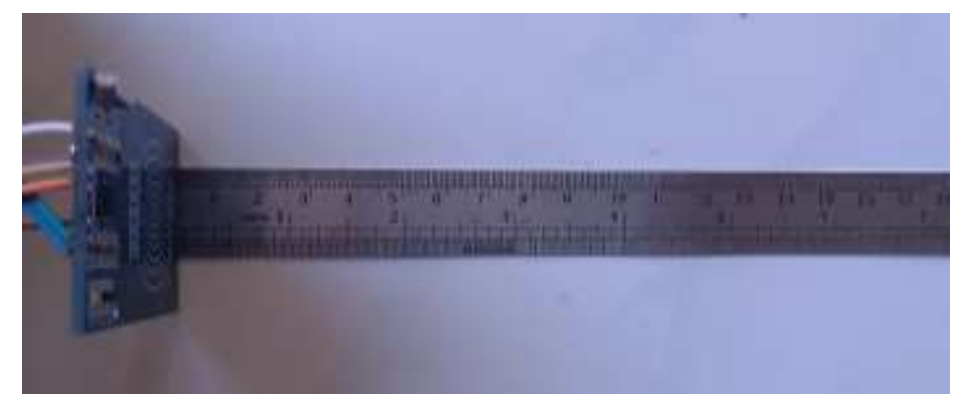

Gambar 5. Posisi pengujian jarak pembacaan tag RFID 


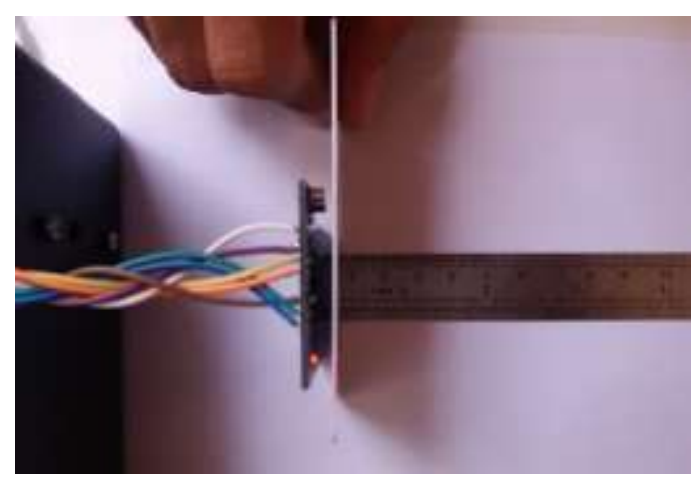

Gambar 6. Pengujian dengan jarak 0,5 cm

Pengujian akan terus dilakukan hingga jarak $8 \mathrm{~cm}$ dengan mengambil 10 kali sampel pengujian pada setiap jaraknya. Dari hasil pengujian yang telah dilakukan, maka didapatkan hasil pengujian jarak yang disajikan dalam Tabel 1 .

Tabel 1. Hasil pengujian jarak pembacaan tag RFID

\begin{tabular}{llllllllllll}
\hline \multirow{2}{*}{ Jarak } & \multicolumn{10}{c}{ Pengujian ke- } & Keterangan \\
\cline { 2 - 6 } & 1 & 2 & 3 & 4 & 5 & 6 & 7 & 8 & 9 & 10 & \\
\hline $1,5 \mathrm{~cm}$ & 1 & 1 & 1 & 1 & 1 & 1 & 1 & 1 & 1 & 1 & Tag terbaca \\
\hline $1,5 \mathrm{~cm}$ & 1 & 1 & 1 & 1 & 1 & 1 & 1 & 1 & 1 & 1 & Tag terbaca \\
\hline $2 \mathrm{~cm}$ & 1 & 1 & 1 & 1 & 1 & 1 & 1 & 1 & 1 & 1 & Tag terbaca \\
\hline $2,5 \mathrm{~cm}$ & 1 & 1 & 1 & 1 & 1 & 1 & 1 & 1 & 1 & 1 & Tag terbaca \\
\hline $3 \mathrm{~cm}$ & 1 & 1 & 1 & 1 & 1 & 1 & 1 & 1 & 1 & 1 & Tag terbaca \\
\hline $3,5 \mathrm{~cm}$ & 1 & 1 & 1 & 1 & 1 & 1 & 1 & 1 & 1 & 1 & Tag terbaca \\
\hline $4 \mathrm{~cm}$ & 1 & 1 & 1 & 1 & 1 & 1 & 1 & 1 & 1 & 1 & Tag terbaca \\
\hline $4,5 \mathrm{~cm}$ & 1 & 1 & 1 & 1 & 1 & 1 & 1 & 1 & 1 & 1 & Tag terbaca \\
\hline $5 \mathrm{~cm}$ & 0 & 0 & 0 & 0 & 0 & 0 & 0 & 0 & 0 & 0 & Tidak Terbaca \\
\hline $5,5 \mathrm{~cm}$ & 0 & 0 & 0 & 0 & 0 & 0 & 0 & 0 & 0 & 0 & Tidak Terbaca \\
\hline $6 \mathrm{~cm}$ & 0 & 0 & 0 & 0 & 0 & 0 & 0 & 0 & 0 & 0 & Tidak Terbaca \\
\hline $6,5 \mathrm{~cm}$ & 0 & 0 & 0 & 0 & 0 & 0 & 0 & 0 & 0 & 0 & Tidak Terbaca \\
\hline $7 \mathrm{~cm}$ & 0 & 0 & 0 & 0 & 0 & 0 & 0 & 0 & 0 & 0 & Tidak Terbaca \\
\hline $7,5 \mathrm{~cm}$ & 0 & 0 & 0 & 0 & 0 & 0 & 0 & 0 & 0 & 0 & Tidak Terbaca \\
\hline $8 \mathrm{~cm}$ & 0 & 0 & 0 & 0 & 0 & 0 & 0 & 0 & 0 & 0 & Tidak Terbaca \\
\hline
\end{tabular}

Dari hasil pengujian jarak pada Tabel 1 dapat diamati bahwa pengujian yang dilakukan (antara pengujian ke-1 sampai pengujian ke-10) pada setiap jaraknya (antara $0,5 \mathrm{~cm}$ sampai 8 $\mathrm{cm}$ ) memiliki hasil pengujian yang sama. Pada jarak $0,5 \mathrm{~cm}$, setiap pengujian menghasilkan output yang sama, yaitu tag terbaca yang ditandai dengan logika 1. Pada jarak pengujian $1 \mathrm{~cm}$, kartu tag masih dapat teridentifikasi dengan baik oleh reader RFID hingga jarak $4,5 \mathrm{~cm}$, sedangkan pada jarak $5 \mathrm{~cm}$, kartu tag mulai tidak dapat teridektifikasi oleh reader RFID. Hal ini disebabkan karena jarak pancar efektif gelombang elektromagnetik reader RFID yang mampu diterima kartu tag sangat terbatas. Berdasarkan datasheet, frekuensi kerja modul RFID Mifare RC522 berada pada frekuensi $13,56 \mathrm{MHz}$ yang mampu mentransfer data sebesar $10 \mathrm{Mbit} / \mathrm{detik}$ melalui protokol SPI dengan kecepatan transfer sebesar 848 kBd secara 2 arah. Oleh karena itu, 
Jurnal IImu Teknik Elektro Komputer dan Informatika (JITEKI)

Vol. 2, No. 2, Desember 2016

dari hasil pengujian jarak pembacaan tag oleh reader RFID dapat disimpulkan bahwa jarak efektif agar tag dapat teridentifikasi oleh reader RFID jenis MIFARE RC522 adalah 4,5 cm.

\subsection{Pengujian Waktu}

Pengujian waktu dilakukan untuk mengetahui berapa waktu yang dibutuhkan oleh reader untuk dapat mengidentifikasi kartu tag berdasarkan jarak tertentu. Pengujian ini mengambil 16 sampel jarak yang diukur setiap $0,5 \mathrm{~cm}$ yang masing-masing jarak diuji sebanyak 10 kali pengujian. Dalam melakukan pengujian waktu, yang harus dipersiapkan adalah alat ukur berupa Stopwatch dan sebuah mistar. Penghitungan waktu dengan stopwatch dilakukan saat kartu tag akan memasuki radius pembacaan reader. Dari hasil pengukuran waktu pembacaan tag akan dihitung waktu rata-rata dari setiap jaraknya. Dari hasil pengujian maka didapatkan hasil pengujian waktu yang disajikan dalam Tabel 2.

Tabel 2. Hasil pengujian waktu pembacaan tag terhadap jarak

\begin{tabular}{|c|c|c|c|c|c|c|c|c|c|c|c|}
\hline \multirow{2}{*}{ Jarak $(\mathrm{cm})$} & \multicolumn{10}{|c|}{ Pengujian waktu ke- (ms) } & \multirow{2}{*}{$\begin{array}{c}\text { Rata- } \\
\text { rata (ms) }\end{array}$} \\
\hline & 1 & 2 & 3 & 4 & 5 & 6 & 7 & 8 & 9 & 10 & \\
\hline 0,5 & 47 & 40 & 40 & 34 & 47 & 34 & 28 & 30 & 47 & 33 & 38 \\
\hline 1 & 33 & 47 & 47 & 33 & 34 & 34 & 31 & 40 & 43 & 42 & 38,4 \\
\hline 1,5 & 33 & 33 & 33 & 40 & 41 & 44 & 33 & 41 & 38 & 45 & 38,1 \\
\hline 2 & 52 & 33 & 40 & 35 & 34 & 50 & 29 & 41 & 32 & 29 & 37,5 \\
\hline 2,5 & 48 & 41 & 33 & 40 & 33 & 42 & 36 & 35 & 31 & 32 & 37,1 \\
\hline 3 & 26 & 40 & 40 & 33 & 34 & 41 & 44 & 41 & 36 & 38 & 37,3 \\
\hline 3,5 & 42 & 40 & 33 & 47 & 46 & 33 & 32 & 43 & 33 & 40 & 38,9 \\
\hline 4 & 50 & 41 & 34 & 41 & 40 & 34 & 32 & 33 & 40 & 44 & 38,9 \\
\hline 4,5 & 33 & 41 & 41 & 44 & 35 & 31 & 40 & 38 & 31 & 40 & 37,4 \\
\hline 5 & 0 & 0 & 0 & 0 & 0 & 0 & 0 & 0 & 0 & 0 & 0 \\
\hline 5,5 & 0 & 0 & 0 & 0 & 0 & 0 & 0 & 0 & 0 & 0 & 0 \\
\hline 6 & 0 & 0 & 0 & 0 & 0 & 0 & 0 & 0 & 0 & 0 & 0 \\
\hline 6,5 & 0 & 0 & 0 & 0 & 0 & 0 & 0 & 0 & 0 & 0 & 0 \\
\hline 7 & 0 & 0 & 0 & 0 & 0 & 0 & 0 & 0 & 0 & 0 & 0 \\
\hline 7,5 & 0 & 0 & 0 & 0 & 0 & 0 & 0 & 0 & 0 & 0 & 0 \\
\hline 8 & 0 & 0 & 0 & 0 & 0 & 0 & 0 & 0 & 0 & 0 & 0 \\
\hline
\end{tabular}

Dapat diamati pada Tabel 2 bahwa hasil pengujian yang dihasilkan memiliki durasi pembacaan tag yang berbeda-beda. Namun tidak terdapat perbedaan waktu yang signifikan antara setiap pembacaan reader. Hasil pengujian pada jarak $0,5 \mathrm{~cm}$ memiliki rata-rata waktu pembacaan tag selama $38 \mathrm{~ms}$. Pada jarak $1 \mathrm{~cm}$ memiliki rata-rata waktu pembacaan selama 38,4 ms. Sampai pada jarak $4,5 \mathrm{~cm}$, waktu yang dibutuhkan untuk membaca sebuah kartu tag oleh reader tidak jauh berbeda. Jika dihitung waktu rata-rata yang dihasilkan dari semua jarak yang diuji, akan menghasilkan waktu pembacaan kartu tag selama $38 \mathrm{~ms}$. Dari hasil tersebut, maka dapat disimpulkan bahwa jarak tidak mempengaruhi lamanya waktu pembacaan tag oleh reader RFID selama tag berada dalam radius gelombang elektromagnetik yang dipancarkan reader. Pembacaan tag hanya berpengaruh pada jauh dekatnya jarak yang membentang antara tag dan reader, tetapi tidak mempengaruhi durasi pembacaan tag.

\subsection{Pengujian Jarak dengan Penghalang}

Pengujian jarak dengan penghalang dilakukan dengan menggunakan penghalang yang diletakkan di antara kartu tag dan reader RFID. Pengujian ini dilakukan untuk mengetahui apakah tag dapat teridentifikasi oleh reader jika dihalangi oleh medium tertentu serta pengaruh yang 
diberikan oleh medium tersebut. Pengujian ini menggunakan beberapa media penghalang, yaitu kaca, kayu, keramik, plastik, acrilic, karet, dan logam. Pernghalang ditunjukkan pada Gambar 7.

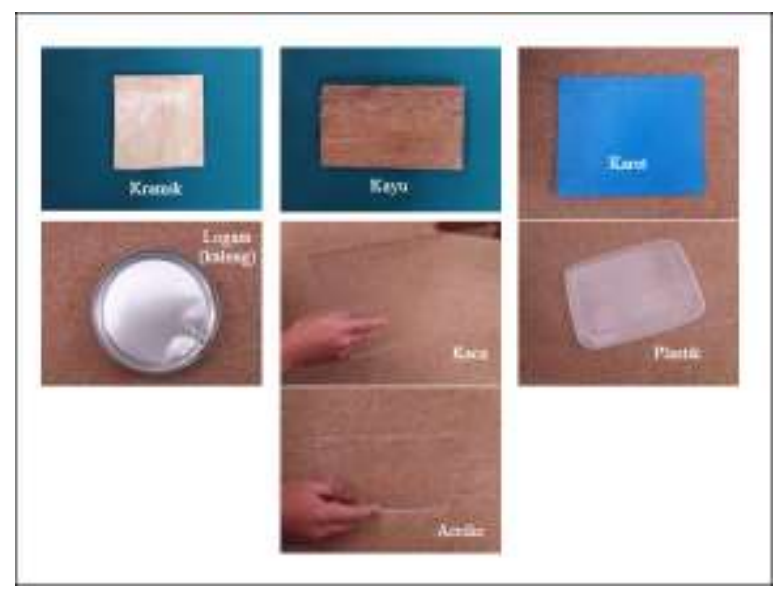

Gambar 7. Penghalang yang digunakan

Masing-masing penghalang yang digunakan akan diuji dengan jarak $0,5 \mathrm{~cm}$ dan kelipatannya hingga jarak $6 \mathrm{~cm}$. Pengujian dengan penghalang ditunjukkan pada Gambar 8 dan Gambar 9.

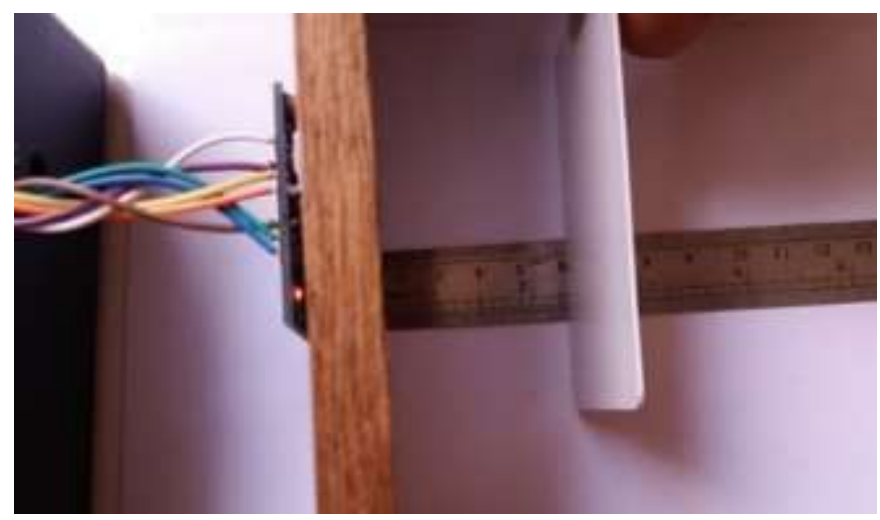

Gambar 8. Pengujian dengan penghalang kayu

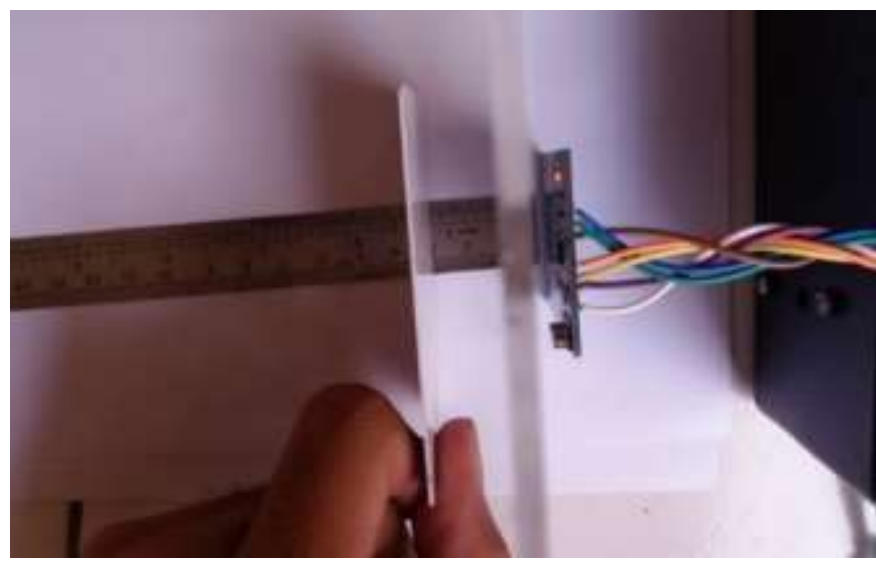

Gambar 9. Pengujian dengan penghalang kaca

Gambar 8 menunjukkan contoh pengujian pembacaan tag yang halangi oleh kayu, sedangkan Gambar 9 yaitu contoh pengujian yang menggunakan kaca sebagai media 
penghalang. Dari hasil pengujian yang telah dilakukan, maka didapatkan hasil pengujian jarak dengan penghalang yang disajikan dalam Tabel 3.

Tabel 3. Hasil pengujian jarak dengan penghalang

\begin{tabular}{|c|c|c|c|c|c|c|c|c|c|c|c|c|c|}
\hline \multirow[b]{2}{*}{ Penghalang } & \multicolumn{12}{|c|}{ Jarak pembacaan (cm) } & \multirow{2}{*}{ Keterangan } \\
\hline & 0,5 & 1 & 1,5 & 2 & 2,5 & 3 & 3,5 & 4 & 4,5 & 5 & 5,5 & 6 & \\
\hline Kaca & 1 & 1 & 1 & 1 & 1 & 1 & 1 & 1 & 1 & - & - & - & Terbaca \\
\hline Kayu & 1 & 1 & 1 & 1 & 1 & 1 & 1 & 1 & 1 & - & - & - & Terbaca \\
\hline Plastik & 1 & 1 & 1 & 1 & 1 & 1 & 1 & 1 & 1 & - & - & - & Terbaca \\
\hline \multirow[t]{2}{*}{ Penghalang } & \multicolumn{12}{|c|}{ Jarak pembacaan (cm) } & Keterangan \\
\hline & 0,5 & & 0,5 & & 0,5 & & 0,5 & & 0,5 & & 0,5 & & \\
\hline Acrilic & 1 & 1 & 1 & 1 & 1 & 1 & 1 & 1 & 1 & - & - & - & Terbaca \\
\hline Logam & - & - & - & - & - & - & - & - & - & - & - & - & $\begin{array}{l}\text { Tidak } \\
\text { terbaca }\end{array}$ \\
\hline Kramik & 1 & 1 & 1 & 1 & 1 & 1 & 1 & 1 & 1 & - & - & - & Terbaca \\
\hline Karet & 1 & 1 & 1 & 1 & 1 & 1 & 1 & 1 & 1 & - & - & - & Terbaca \\
\hline
\end{tabular}

Tabel 3 menunjukkan bahwa setiap bahan menghasilkan jarak pembacaan yang sama kecuali penghalang jenis logam. Pengujian pembacaan kartu tag dengan penghalang logam tidak dapat menghasilkan pembacaan, walapun kartu tag didekatkan hingga $0,5 \mathrm{~cm}$. Hasil ini membuktikan bahwa medium berbahan logam dapat menghalangi pengidentifikasian reader terhadap kartu tag. Bahan logam dapat mengurangi fluks medan magnet sehingga pada percobaan ini logam terlihat menghalangi radiasi gelombang elektromagnetik yang dipancarkan reader RFID untuk dapat diterima oleh kartu tag. Akibatnya, tag tidak dapat memberi respon balik terhadap reader berupa pengiriman sinyal yang memuat nomor ID dari tag tersebut. Oleh karena itu, dari hasil pengujian dapat disimpulkan bahwa semua penghalang yang digunakan dalam pengujian ini tidak tidak berpengaruh pada jarak pembacaan kartu tag oleh reader RFID, kecuali bahan berjenis logam.

\section{Kesimpulan}

Dari hasil penelitian yang telah dilakukan, maka dapat diambil kesimpulan:

1.Sistem presensi mahasiswa berbasis RFID menggunakan Raspberry Pi merupakan sistem presensi yang dibuat dengan mengkombinasikan teknologi RFID jenis MIFARE RC522 sebagai komponen utama presensi dan Raspberry $\mathrm{Pi}$ sebagai microcontroller sekaligus server bagi sistem presensi.

2. Terdapat 3 hal yang harus dilakukan dalam merancang sistem presensi mahasiswa berbasis RFID, yaitu merancang program Raspberry $\mathrm{Pi}$ agar dapat berfungsi sebagai microcontroller, merancang database penyimpan data pada server Raspberry $\mathrm{Pi}$, dan merancang program website untuk menampilkan hasil presensi. Dari hasil tersebut, masing-masing perancangan diimplementasikan pada hardware dan software sebagai bahan hingga membentuk sebuah sistem presensi.

3. Dari hasil pengujian sistem yang dilakukan, maka diperoleh jarak maksimal identifikasi yang dapat dilakukan reader RFID terhadap kartu tag yakni sejauh $4,5 \mathrm{~cm}$ dengan rata-rata waktu selama $38 \mathrm{~ms}$. Pengujian sistem membuktikan bahwa jarak antara reader dan tag tidak mempengaruhi waktu identifikasi reader terhadap kartu tag selama tag berada pada zona radiasi gelombang radio yang dipancarkan reader. Hasil pengujian dengan media penghalang membuktikan bahwa bahan jenis logam dapat menghalangi laju gelombang radio yang dipancarkan reader RFID untuk sampai kepada kartu tag, sedangkan penghalang jenis lain (yang digunakan dalam penelitian ini) tidak berpengaruh pada hasil identifikasi reader pada kartu tag. 
Referensi

[1] Anton Cabon. (2016). Gelombang Elektromagnetik. Diperoleh dari: http://www.antoncabon.us/2016/04/pengertian-gelombang-elektromagnetik.html (Diakses 11 September 2016)

[2] Belajar Python. (2015). Tipe data Python. Diperoleh dari: http://www.belajarpython.com/2015/05/tipe-data-python.html (Diakses 08 September 2016)

[3] Cahyadi D. (2009). Desain Sistem Absensi PNS Berbasis Teknologi RFID. Samarinda : Universitas Mulawarman

[4] Deprito. (2012). Arsitektur Raspberry Pi. Diperoleh dari: https://elmoony.files.wordpress.com/2012/12/schematic-skema-raspberrypi.png? $\mathrm{w}=424 \& \mathrm{~h}=484 \& \mathrm{crop}=1$ (Diakses 24 November 2015 )

[5] Diyhacking. (2015). Pin header GPIO Raspberry Pi. Diperoleh dari: https://diyhacking.com/raspberry-pi-gpio-control/ (Diakses 8 September 2016)

[6] Finkenzeller K. (2010). Fundamentals and Application in Contactless Smart Cards, Radio Frequency Identification and Near-Field Communication. Dalam RFID Handbook, Third Edition. Munich: John Wiley \& Sons, Ltd.

[7] Helenturvey. (2015). Conector RJ45. Diperoleh dari: http://www.helenturvey.com/apa-ituconnector-ri45-atau-modular-plug/ (Diakses 28 September 2016)

[8] Igoe Tom (2012). Getting Started with RFID. USA: O'Reilly Media, Inc.

[9] Instructable. (2016). Attendance System Using Raspberry Pi and NFC-Tag. http://www.instructables.com/id/Attendance-system-using-Raspberry-Pi-and-NFC-Tagr/?ALLSTEPS (Diakses 26 Maret 2016)

[10] Mike Grusin. (2010). Serial Pheripheral Interface (SPI). Diperoleh dari: https://learn.sparkfun.com/tutorials/serial-peripheral-interface-spi (Diakses 31 Agustus 2016)

[11] Nainan S., Parekh R., Shah T. (2013). RFID Technology Based Attendance Management System. International Journal of Computer Science Issues (IJCSI). 10(1): 516 - 521 .

[12] Noprianto. (2002). Python dan Pemrograman Linux. Yogyakarta: C.V. Andi Offset

[13] Pinout. (2016). The comprehensive GPIO Pinout guide for the Raspberry Pi. http://pinout.xyz/ (diakses 28 Juni 2016)

[14] Rakhman E., Candrasyah F. \& Sutera F.D. (2014). Raspberry Pi-Mikrokontroler Mungil yang Serba Bisa. Yogyakarta: C.V. Andi Offset.

[15] Raspberry $\mathrm{Pi}$ Indoneisa. (2015). Pengertian Raspberry Pi. Diperoleh dari: http://www.raspberryindonesia.com/ (diakses 22 November 2015)

[16] Raspberry Pi. (2015). Spesifikasi Raspberry Pi 2 model B+. Diperoleh dari: https://www.raspberrypi.org/products/model-b-plus/ (diakses 23 November 2015)

[17] Raspberry Pi. (2016). Enabling The SPI Interface on The Raspberry Pi. http://www.raspberrypi-spy.co.uk/2014/08/enabling-the-spi-interface-on-the-raspberry-pi/ (diakses 24 April 2016)

[18] Raspberry $\mathrm{Pi}$ web server. (2016). Using MySQL on a Raspberry Pi. http://raspberrywebserver.com/sql-databases/using-mysql-on-a-raspberry-pi.html (diakses 12 Mei 2016)

[19] Raspberry Pi. (2016). How to Autorun a Python script on boot using systemd. http://www.raspberrypi-spy.co.uk/2015/10/how-to-autorun-a-python-script-on-boot-usingsystemd//(diakses 20 Mei 2016)

[20] Richardson M. \& Wallace S. (2013). Getting Started with Raspberry Pi. USA: O'Reilly Media, Inc.

[21] Robotic Controls. (2013). Tampilan OS Raspbian. Diperoleh dari: http://roboticcontrols.com/sites/default/files/images/raspbian-screenshot.png (Diakses 18 November 2015)

[22] Schmidt M. (2014). Raspberry Pi A Quick-Start Guide Second Edition. USA: The Pragmatic Programmers, LLC.

[23] Terminaltechno. (2015). Pengertian RFID. Diperoleh dari: http://terminaltechno.blog.uns.ac.id/2011/03/13/rfid-radio-frequency-identification/ (diakses 22 November 2015) 
Jurnal IImu Teknik Elektro Komputer dan Informatika (JITEKI)

Vol. 2, No. 2, Desember 2016

[24] Wibisono S.T. (2015). Implementasi Teknologi Raspberry Pi dan RFID pada Piranti Penyimpanan "Deposit Box". Semarang: Universitas Diponegoro. 